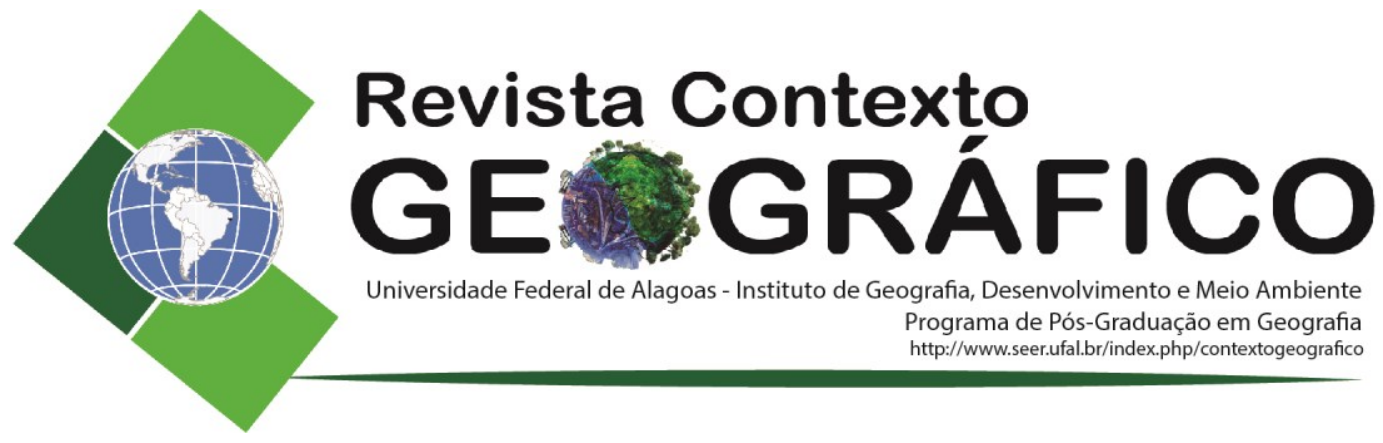

\title{
IMPACTOS DO USO DA TERRA NO COMPLEXO ESTUARINO-LAGUNAR MUNDAÚ-MANGUABA - ALAGOAS - BRASIL
}

\author{
Sinval Autran Mendes Guimarães Júnior \\ Universidade Federal de Alagoas - LGA-IGDema-UFAL, \\ Maceió, AL, Brasil \\ sinval.autran@igdema.ufal.br \\ Melchior Carlos do Nascimento \\ Universidade Federal de Alagoas - LGA-IGDema-UFAL, \\ Maceió, AL, Brasil \\ melchior.nascimento@igdema.ufal.br \\ Diego José Ramalho Pimentel da Silva \\ Universidade Federal de Alagoas - LGA-IGDema-UFAL, \\ Maceió, AL, Brasil \\ diego_rama@ig.com.br
}

\begin{abstract}
RESUMO - A pesquisa teve como objetivo mapear e quantificar os impactos do uso da terra no Complexo Estuarino-Lagunar Mundaú-Manguaba (CELMM), localizado na parte central do litoral do estado de Alagoas. A qualificação dos impactos teve como referência o mapeamento do uso da terra e da cobertura vegetal, realizada a partir da interpretação visual direta de imagens em falsa cor do satélite SPOT, nas bandas R2G3B4, com resolução espacial de $10 \mathrm{~m}$, ano de 2002 . Os dados foram georreferenciados, editados e planimetrados no programa Vista SAGA - versão 2007, identificando assim, os seguintes impactos do uso da terra: muito forte baixo (cana-deaçúcar), $30,12 \%$ e muito forte médio (áreas urbanizadas), $11,79 \%$, sendo este, o mais preocupante, em face do seu avanço sobre o cultivo do coco-da-baía, a floresta estacional e as formações pioneiras (marinhas e flúvio-marinhas). Outros impactos do uso da terra também foram identificados como fraco-médio (pastagens) e fraco alto (coco-da-baía), totalizando pouco mais de $15 \%$ do CELMM. A pesquisa aponta para a necessidade de gerenciamento integrado do CELMM, devido ao fato que os impactos do uso da terra têm contribuído diretamente para a degradação ambiental, tais como, a erosão das encostas e a sedimentação e poluição dos cursos d'água.
\end{abstract}

Palavras-chave: Impactos Ambientais; Geoprocessamento; Uso da Terra.

\section{IMPACTS OF LAND USE IN THE ESTUARINO-LAGUNAR COMPLEX MUNDAÚ-MANGUABA - ALAGOAS - BRAZIL}

\begin{abstract}
The intention of this research was to map and quantify the impacts of land use on the Mundaú-Manguaba Estuary-Lagunar Complex (CELMM), located in the central part of Alagoas coast. The classification of the impacts was based on the mapping of land use and vegetation covering, based on the direct visual interpretation of false SPOT images in the bands R2G3B4, with a spatial resolution of $10 \mathrm{~m}, 2002$. The data were geo-referenced, edited and planed in the Vista SAGA program - 2007 version, thus identifying the following impacts of land use: very strong low (sugarcane), 30,12\% and very strong moderate (urbanized areas), 11,79\%, being this is the most worrisome due to its advance on the cultivation of coconut palms, the seasonal forest and the pioneer formations (marine and fluvial-marine). Other impacts of land use were also identified as low to medium (pasture) and low (coconut palms), totalizing just over $15 \%$ of CELMM. The research points to the need for integrated management of CELMM, due to the fact that the impacts of land use have directly contributed to environmental degradation, such as slope erosion and sedimentation and defilement of water courses.
\end{abstract}

Keywords: Environmental Impacts; Geoprocessing; Land use. 


\section{INTRODUÇÃO}

Situado na parte central do litoral alagoano, abrangendo áreas dos municípios de Maceió, Marechal Deodoro, Pilar, Rio Largo, Satuba, Santa Luzia do Norte e Coqueiro Seco, o Complexo Estuarino-Lagunar Mundaú-Manguaba - CELMM (Figura 1) apresenta rica variedade de fauna e flora, diversidade de ambientes naturais e uma densa história, que remonta aos primórdios da colonização do Brasil, quando viviam várias tribos indígenas, em especial, a dos Caetés. Nos últimos trinta anos, a valorização das terras, impulsionadas pela beleza da paisagem, vêm determinado uma expressiva ocupação, sobretudo por empreendimentos do setor imobiliário voltados para o turismo de Sol \& Mar, gastronomia, recreação e lazer. Aliados a esses fatores, os investimentos públicos realizado em infra-estrutura, destacando-se, a implantação e operação da Salgema Indústrias Químicas S/A., atual Braskem (empresa química e petroquímica brasileira), do Polo Cloroquímico de Alagoas (PCA), da Unidade de Processamento de Gás Natural de Alagoas (UPGN-AL) e da rodovia estadual AL-101 Sul, como também, a sua duplicação. Somados a isso, a crescente oferta de serviços, se refletem cada vez mais, no aumento da demanda turística e de segunda residência, que tem como conseqüência a maior pressão sobre o conjunto dos seus atrativos naturais. Essa condição pode ser constada pela criação de quatro unidades de conservação que estão inseridas no CELMM, as Áreas de Proteção Ambiental de Santa Rita e do Catolé e Fernão Velho, a Reserva Ecológica do Saco da Pedra e o Parque Municipal de Maceió.

Nesta pesquisa, pretende-se demonstrar os impactos do uso da terra e sua interferência na transformação da paisagem e nas condições naturais do CELMM. Os acontecimentos decorrentes desta constatação têm se revelado de maneira abusiva e predatória, principalmente na geração de impactos ambientais do uso da terra que comprometem a proteção dos recursos naturais. As consequências tem sido de ordem diversa e generalizada, que vai desde a descaracterização da paisagem com a concentração de residências até a perda de navegabilidade nos canais interlagunares, face ao aumento do assoreamento sem mencionar a gravidade da poluição das águas que tem contribuído para a diminuição e extinção da fauna e da flora.

Todo esse panorama ora mencionado, faz parte da atual realidade do CELMM. As conseqüências desse processo têm resultado num quadro preocupante, representado por uma série de impactos ambientais, bem como têm contribuído para uma acentuada queda na qualidade de vida da sua população, sobretudo a de baixa renda.

Figura 1. Localização do Complexo Estuarino-Lagunar Mundaú-Manguaba - CELMM

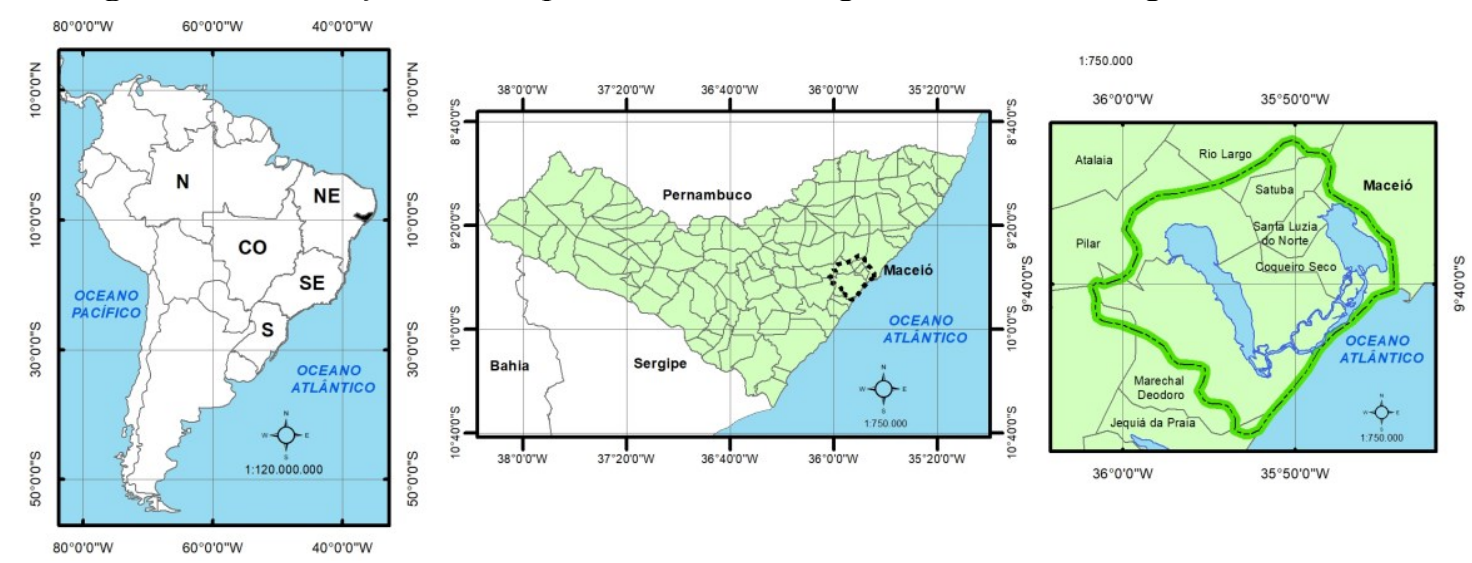

\section{ÁREA DE ESTUDO}

O Complexo Estuarino Lagunar Mundaú-Manguaba (CELMM) possui uma das mais belas e expressivas paisagens do litoral alagoano, tendo despertado inúmeros interesses na exploração e aproveitamento dos seus recursos naturais, voltados, sobretudo, para o desenvolvimento de 
atividades turísticas, gastronômicas, recreativas e de lazer. Constitui o CELMM, um dos mananciais de vida aquáticas mais importantes do Nordeste do Brasil, justo pela diversidade de espécies, como beleza cênica das lagunas Mundaú e Manguaba e dos canais que as interligam, além de remanescentes florestais e de expressivos manguezais.

O CELMM está situado entre os paralelos $09^{\circ} 34^{\prime} 00^{\prime}$ e e $09^{\circ} 48^{\prime} 00^{\prime \prime}$ de latitude Sul, e os meridianos $035^{\circ} 44^{\prime} 00^{\prime \prime}$ e $035^{\circ} 58^{\prime} 00^{\prime \prime}$ de longitude Oeste de Greenwich. As suas margens estão situadas as cidades de Maceió, Santa Luzia do Norte, Coqueiro Seco, Pilar e Marechal Deodoro. Formam o CELMM as lagunas Mundaú e Manguaba e a zona de canais (LIMA, 1990).

A laguna Mundaú possui aproximadamente $23 \mathrm{~km}^{2}$ e tem como principal contribuinte, o rio homônimo, enquanto a laguna Manguaba possui aproximadamente $34 \mathrm{~km}^{2}$ e tem como principal contribuinte o rio Paraíba do Meio. Neste sistema a intrusão de águas costeiras é reduzida variando os valores de salinidade entre zero e 5\% (ALAGOAS, 1995). As duas lagunas são interligadas pelos canais (Norte e Sul), que convergem para a boca da barra formando o CELMM.

O CELMM está sob influência climática marcado por duas estações. No período entre março e agosto, na estação chuvosa, as precipitações médias mensais, alcançam $1000 \mathrm{~mm}$, nesse período, ocorrem $75 \%$ das precipitações anuais. O período de setembro a fevereiro é caracterizado pela estação seca, sendo que as precipitações são ainda menores de outubro a janeiro correspondendo a menos de $8 \%$ do total anual. Nos anos mais secos, as precipitações chegam a $1.500 \mathrm{~mm}$ e nos mais chuvosos a $2.000 \mathrm{~mm}$, enquanto as temperaturas médias oscilam entre $25^{\circ} \mathrm{C}$ e $26^{\circ} \mathrm{C}$, com máximas de $31^{\circ} \mathrm{C}$ e mínimas de $19^{\circ} \mathrm{C}$. Predominam ventos alísios constantes, de velocidade baixa a moderada variando de 4,8 a $7,9 \mathrm{~km} / \mathrm{h}$, no sentido NE, entre outubro e fevereiro, no sentido SE; entre março e agosto. Com essas características, o clima se enquadra no tipo As` (tropical chuvoso com verão seco e chuvas de outono-inverno) segundo a classificação de Koppen, adaptada ao Brasil (ALAGOAS, 1992; 1994).

A porção central abrangida pelo CELMM, faz parte da bacia sedimentar de Alagoas, que apresenta uma série de feições morfológicas resultante do afogamento de antigos vales e estuários, decorrentes da evolução paleogeográfica ocorridas durante o quaternário. As condições geológicas e geomorfológicas, juntamente com dinâmica costeira ocorrida nesse período, levaram ao afogamento dos estuários rios Mundaú e Manguaba, originando as lagunas e seus canais e as várias feições morfológicas presentes na planície costeira atual (LIMA, 1990).

Do ponto de vista litológico, o CELMM está localizado na Bacia Sedimentar Alagoas, compreendendo pelo graben assimétrico de Maceió (FEIJÓ, 1994). Na porção noroeste, O CELMM apresenta um sistema de falhas com direção NW-SE (Noroeste-Sudeste) que limitam a bacia com afloramento do cristalino ou rochas (MARQUES, 1987). Estas falhas podem ser visualmente identificadas no encachoeiramento dos rios Mundaú e Paraíba do Meio, nas proximidades das cidades de Rio Largo e Atalaia (LIMA, 1990; ALAGOAS, 1997).

A partir do embasamento cristalino, as unidades litográficas são representadas da base para o topo pelas formações: Ponta Verde, Coqueiro Seco e Muribeca, esta última classificada de Formação Poção (FEIJÓ, 1994). As lagunas Mundaú e Manguaba estão entalhadas no curso inferior dos rios Mundaú e Paraíba do Meio, entre as superfícies dos tabuleiros se comunicando com o oceano através de canais na planície costeira (ALAGOAS, 1997).

As margens das lagunas Mundaú e Manguaba se apresentam sinuosas e são limitadas diretamente pelo sopé das encostas, por planícies flúvio-lagunares, como: várzeas, reentrâncias (ou enseadas) e a "ressaca", certo tipo de enseada mais fechada, incluindo ainda as planícies das aluviões, onde situam os deltas interlagunares, justapostos ao curso inferior dos rios Mundaú e Paraíba do Meio, até o sopé das encostas dos tabuleiros da formação barreiras. Próximo às lagunas ocorrem planícies lamacentas, onde o influxo de argilas e siltes de carga fluvial sobrepujam a capacidade dispersora do corpo lagunar. Nesta planície de frente deltaíca é marcante a presença de mangues exuberantes (MARQUES, 1980; ALAGOAS, 1997).

Segundo Marques (1980), o elevado índice pluviométrico é um traço marcante, e um dos principais elementos responsáveis por certos aspectos dominantes na abrangência do CELMM, a exemplo da vegetação de Mangues e das matas, que se apresentam sempre 
verdes e diversificadas, bem como uma rica rede hidrográfica caracterizada pela influência dos rios Paraíba do Meio, Mundaú, Sumaúma Grande e do Riacho dos Remédios. Além desses cursos d'água, fazem parte do sistema hidrográfico que influência nas condições naturais da área de estudo, o riacho do Giz e muitos outros que descem dos tabuleiros desaguando nas lagunas ou nos canais. Por extensão temos a presença das lagunas Mundaú e Manguaba, que devido às influências dos seus rios formadores, rio Mundaú e Paraíba do Meio, acaba por influenciar também na dinâmica natural dos canais interlagunares, contribuindo assim, até certo ponto num maior ou menor processo de assoreamento. Esses rios, lagunas e cursos citados encontram-se bastante influenciados pelas atividades humanas ou decorrentes delas, destacando-se: (a) os desmatamentos nas proximidades de suas cabeceiras e ao longo de suas margens; (b) o assoreamento do leito dos rios, riachos, lagunas e canais e (c) a poluição das águas causada pelos dejetos das atividades industriais e pelo uso de agroquímicos nas lavouras comerciais (MARQUES, 1980).

Nos tabuleiros, a cana-de-açúcar se encarregou de realizar uma série de fatos que levaram praticamente a destruição das condições naturais do CELMM, em especial, a cobertura vegetal e os solos.. Em contrapartida, nas áreas próximas as lagunas, ilhas, canais interlagunares e litoral, os loteamentos e as casas de veraneio (segunda residência) construído em locais de grande sensibilidade ecológica provocaram também profundas alterações no equilíbrio e na sua dinâmica natural, acarretando assim, prejuízos na sua maioria das vezes irreversíveis.

Segundo Lima (1990), a laguna Manguaba sem dúvida se trata de uma antiga restinga, demonstrando ter passado por movimentos subsidentes que lhe causaram trechos deprimidos, sobre influencia do horst de Satuba, mostrando em sua geomorfologia que não foi interrompida, como a Mundaú. Esta ausência na Manguaba dá-lhe a possibilidade de ser mais comprida, Nas bordas, na parte alta, leva a deduzir que se alarga mais junto a cidade de Pilar, com alinhamento orientado até o mar, na forma estrutural básica de um "Y" (LIMA, 1990).

Ainda segundo Lima (1990), a parte da laguna Manguaba que se apresenta mais rasa fica no litoral, indicando o soerguimento atuante na subsuperfície, que lhe proporcionou um amplo entulhamento por causa dos processos mais recentes, acabando por modelar seu espaço lagunar. A sua superimposição induz o rio Paraíba, inserido nos tabuleiros marca o ciclo erosivo "Paraguaçu" que King apud LIMA (1990), estabeleceu para os vales inferiores desse tipo. O rio Paraíba-do-Meio, semelhante ao Mundaú, forma uma planície de inundação, mas não tem as mesmas proporções e formas de relevo, no caso, mais amplas e rasas. $\mathrm{O}$ afogamento que aqui exerce seu papel perfeitamente notado e, principalmente, durante os meses do inverno quando se faz coadjuvado pelas enchentes, pois o pequeno "delta inferior" do Sumaúma, sujeito a toda inundação da laguna, comprova, como os demais que se encontram formando a rede dos afluentes lacustres, como é o caso do Giz e do próprio Paraíba-do-Meio, exercendo maior papel formador do ambiente em estudo (LIMA, 1990).

A cobertura vegetal do CELMM é constituída por remanescentes florestais, na sua maioria, confinados em fundo de vales e encostas. Ocorre também, vegetação em estágio de sucessão natural, surgidas com a derrubada da vegetação original. Ocorrem ainda, as Formações Marinhas (vegetação de praias), Flúvio-lacustres (vegetação de várzeas) e Flúvio-marinhas (vegetação de mangue). Esta última em especial, quando ocorrem as margens dos cursos dos rios, no entorno das lagunas, nos canais e nas ilhas, têm sido aterradas, trazendo sérios prejuízos para a dinâmica ambiental, face ao assoreamento dos canais. Quanto ao uso da terra, observamse a presença dos coqueirais, sujeitos a devastação, pela implantação de loteamentos e condomínios, como também, a cana de açúcar, que outrora substituiu praticamente toda a vegetação florestal que recobria os tabuleiros. O beneficiamento da cana-de-açúcar tem produzido uma grande quantidade de efluentes que, mesmo sendo parcialmente lançados nos cursos de água, levam a degradação (ALAGOAS, 1979).

O êxodo rural, devido ao desemprego no campo, trouxe a Maceió grande quantidades de pessoas que, sem moradia, foram se instalar ás margens das lagunas, em especial a Mundaú. Por outro lado, a implantação de uma grande indústria química às suas margens afastou os moradores de melhores condições financeiras que preferiram residir nas proximidades praias de 
Pajuçara e Ponta Verde, que abriga hoje em suas redondezas uma grande parte da população de baixa renda. Outro fator econômico de grande relevância é o setor pesqueiro, que absorve um percentual elevado de mão-de-obra de baixíssima capacitação tecnológica. A fauna existente nas lagunas Mundaú e Manguaba serviram e servem de sustento a uma parte da população. Na laguna Mundaú, vale destacar a cata do sururu, molusco que ajudou a divulgar, o estado de Alagoas como o de maior quantidade dessa iguaria no cenário nacional, mas também como grande fonte de proteínas para a sua população.

A indústria sucroalcooleira é a fonte de maior importância para economia do estado, é dela que sai os produtos de maior participação na balança comercial alagoana. Na bacia do rio Mundaú, dos 13 municípios estabelecidos em Alagoas, há nas margens dos rios e de seus afluentes, cinco sedes municipais: Santana do Mundaú, União dos Palmares, Branquinha, Murici e Rio Largo. Indústrias do setor sucro-alcooleiro estão instaladas no CELMM, dentre elas, a Usina Serra Grande S/A, a Cia Açucareira Usina Lajinha, a Usina Santa Clotilde e a Usina Central Utinga Leão. Estão instalados também diversos matadouros, com destaque para o Matadouro e Frigorífico de Alagoas S/A (Mafrial), além de diversas cerâmicas e pedreiras (ALAGOAS, 1997). As cerâmicas existentes no curso inferior dos rios Mundaú e Paraíba-do- Meio, segundo Barretos (1988), as argilas são usadas para a fabricação de blocos de tijolos e telhas, para enchimento ou estruturas, havendo também alguma produção de manilhas destinadas ao mercado local. Uma produção, fisicamente pequena, mas e grande valor, é a de refratários e pisos vidrados, que atende a demanda da construção civil e ao setor industrial, tanto para o mercado local quanto para o nacional. A interferência dessa atividade na natureza está relacionada ao sistema que queima através de fornos de lenha, apesar de estar tornando-se rara, em função da grande distância que é trazida a matéria prima, a pequena eficiência da maioria dos fornos usados pelas pequenas cerâmicas deve ter sido responsável por uma fração importante do desmatamento (MARQUES, et al., 2000).

Ainda segundo Marques et al. (2000), na área urbana do município de Maceió, destacam-se algumas instalações que desenvolvem atividades econômicas de retirada da areia lavada no leito e nas margens do rio de Carrapatinho no bairro de Rio Novo. Na margem direita da laguna Manguaba, no município de Pilar, identifica-se a atividade canavieira, no município de Marechal Deodoro, além da canavieira, a criação de porcos, como a exploração de gás natural, com inúmeras perfurações da Petrobrás através da UPGN - Unidade Processadora de Gás Natural. Em quase toda a extensão do CELMM é predominante á atividade da agricultura de coco-da-baia (Cocus nucifera) consorciada à agricultura de subsistência, além do artesanato de renda, palha e lata, formam assim atividades complementares à pesca. Na zona dos canais, ainda no município de Marechal Deodoro, observa-se as seguintes atividades; como: construção de estradas e pontes com vãos estreitos e aterro de áreas alagáveis, gerando problemas e modificações na hidrodinâmica dos canais; outro fator é o abandono de instrumentos de pesca fixos (caiçaras, tapagens e currais), nos canais gerando o acumulo de sedimentos e modificando a circulação da água (MARQUES, et al., 2000).

Destaca-se também, a implantação do Pólo Cloroquímico de Alagoas (PCA) localizado no alto do tabuleiro de Marechal Deodoro com as seguintes unidades instaladas: fábricas de PVC, cloro, soda e de dicloretano; a Salgema, Indústrias Químicas S/A, atual Braskem; o oleoduto Pilar/Bamac, da Petrobrás, a Unidade de Processamento de Gás Natural de Alagoas (UPGNAL), localizado nas proximidades da fazenda Lamarão, em Pilar, interligada aos Portos de Maceió - Alagoas e de Suape - Pernambuco, através do Gasoduto Alagoas-Pernambuco Gasalpe (ALAGOAS, 1997).

\section{REVISÃO DA LITERATURA}

Como acontece com outras categorias de estudo, a paisagem de uma determinada área, se constitui num elemento de análise e compreensão sobre sua estrutura, dinâmica, percepção, tipos, formas de organização e origem, seja pelas condições naturais ou criadas a partir das interferências humanas. 
Visto sob esse aspecto, o estudo sobre a paisagem e a dinâmica natural de um ambiente, tornam-se muito mais relevante nos dias atuais, podendo ajudar a entender e a solucionar inúmeros problemas relacionados ao (re) ordenamento do território, principalmente quando relacionados às questões ecológicas, econômicas e sociais, em que os seus reflexos se traduzem em crescente pobreza, agressões, poluição e descasos para com os recursos naturais. De fato, a exploração constante e de forma predatória dos recursos naturais vem atropelando a ética, o bem estar e o equilíbrio da natureza, comprometendo assim, a sobrevivência do próprio homem. Daí não ser simples, a tarefa de entender a dinâmica natural de uma paisagem, sua criação e sua organização (ANDRADE, 1977).

Diante desta perspectiva, para se chegar a uma análise sistêmica, é necessário entender a paisagem, através da inter-relações dos seus elementos naturais ou antrópicos, que nela estão contidos e facilmente perceptíveis, em toda a sua extensão. Sendo assim, tais elementos poderão determinar a estrutura e a dinâmica que dão significado, forma e sentido a paisagem, dentro do conjunto de evolução interna e externa apresentado. (SANTOS, 2009).

A paisagem é composta por uma série de elementos naturais e humanos que se articulam entre si, ao longo da história de uso e ocupação do solo (DOLLFUS, 1973).

Nesse contexto, é que surge um universo de combinações sobre os recursos naturais e, portanto, sobre os elementos da paisagem, demonstrando-se assim, parte da sua dinâmica, pois o todo de seu conjunto será articulado ao longo da história do próprio espaço. Desse modo, a paisagem é o resultado da constante combinação de elementos naturais e humanos presentes num determinado espaço, onde não se faz referência apenas aos recursos naturais do conjunto observado, na qual se percebe ou que a visão consegue apreender sobre o mesmo, mas a tudo o que está também por trás dela, com todos os seus significados e elementos dinâmicos em constantes inter-relações (LIMA, 1990).

A compreensão da dinâmica natural ou não de uma paisagem, deve ser observada a partir do resultado de movimentos sociais no contexto das suas atividades produtivas, realizadas ao longo da sua história, pois o homem é o maior agente transformados dos espaços naturais e, portanto das paisagens, embora sob escala diferente da natural (SANTOS, 2008).

Ainda segundo Santos (2009), a exemplo do espaço humanizado, as paisagens são determinadas pelas relações permanentemente estabelecidas entre o homem e o meio, originando diante destas relações, um mosaico de cores, formas, funções e sentidos. Assim, uma paisagem pode ser o resultado da intervenção de múltiplas forças e da interação de processos naturais ou humanos ocorridos no tempo e no espaço. É, pois reflexo de uma visão sociocultural do homem diante de um sistema produtivo, dependente de forças e formas particulares de organização, que se tornam obsoletas ou desaparecem quando não são mais adequadas ao processo de produção e de crescimento econômico. Essa constatação demonstra que há na paisagem uma associação dinâmica, formada por um complexo conjunto de forças, que agem e se reproduzem na presença de múltiplos fatores condicionantes, organizando-se e interrelacionando-se mutuamente, para que possam originar ou possibilitar a formação das estruturas encontradas nos sistemas naturais, como é observado dentro dos ecossistemas (SANTOS, 2008; 2009). A associação ora mencionada, o Complexo Estuarino Lagunar Mundaú-Manguaba, quando se observa a interação das comunidades que ali habitam com os ecossistemas naturais: manguezais, restingas entre outros.

Segundo Dollfus (1991), quanto à tipologia, costumam-se classificar as paisagens com suas respectivas dinâmicas segundo dois grupos principais: o primeiro formando pelas paisagens naturais, como sendo aquelas constituídas pelo domínio dos componentes do meio natural e dotadas de uma dinâmica própria; e o segundo as paisagens artificiais, também conhecidas como culturais, representadas pelos aspectos dominados pelas marcas da ocupação humana. Assim, cada paisagem é identificada de acordo com a predominância de alguns elementos que as caracterizam dentro de um quadro apresentado pelo meio ambiente onde estão inseridas, levandose em consideração o arranjo dos seus elementos envolvidos, que são eles, os reflexos mais visíveis do espaço As atividades humanas têm resultado em formas crescentes de ocupação e uso do solo, que variam em função e intensidade, de acordo com o período da história social e 
econômica, sob certas condições naturais, pela qual a ação do homem sobre os recursos da natureza, tende sempre a transformar o meio natural em meio geográfico (DOLLFUS, 1991).

Neste sentido, compreende-se que o uso da Terra se faz de forma direta e constante através da sua redefinição, tanto para a agricultura como para a implantação urbana, na geração de energia pelas hidroelétricas, exploração mineral ou industrial. Independente do tipo de uso definido, as reações ambientais são diversas e as conseqüências em geral negativas para o meio (SANTOS, 2009).

Segundo Drew (1994), as transformações do espaço natural, só foram se tornar frequentes e intensas a partir do Neolítico, sobretudo através das atividades produtivas que constituíram os primeiros passos decisivos para o uso do solo e o controle da natureza, embora, o seu papel como agente transformador do espaço e sua conseqüências sobre o uso do solo, date apenas de 6.500 à 7.000 anos a.C. É a partir das atividades agrícolas que a ação humana tem se manifestado de maneira cada vez mais intensa e prejudicial aos seus recursos naturais, face aos seus efeitos conjugados, proporcionado sobretudo pelo crescimento demográfico e o progresso tecnológico, aliados ainda, aos avanços científicos em cada período da sua história. (DOLLFUS, 1991).

$\mathrm{O}$ aumento da produtividade, mencionado acima, tem sido a meta de todas as atividades que requerem o consumo do espaço natural, somados a isso, a idéia de aumento na produção e sucesso econômico sugere uma série de ajustamentos que são feitos nos modos de produção (SANTOS, 2009). Por outro lado, a capacidade de inovar, é a principal responsável pela evolução das atividades envolvidas obedecendo a certos critérios funcionais produzidos num determinado ambiente. Isto ocorre segundo Andrade (1993), pela atuação da sociedade sobre as condições naturais do meio, transformando-as e possibilitando a formação de uma nova natureza, não idêntica á primitiva, mas com algumas de suas semelhanças. Compreende-se, dessa forma, que há uma variação na apresentação e nas formas de organização dos recursos naturais e, consequentemente, na forma de uso e ocupação da terra em cada contexto.

Ainda segundo Andrade (1993), as características mencionadas acima, fornece uma dimensão espacial de ocupação da sociedade e de suas atividades produtivas, mas torna-se também, a base principal da maioria dos problemas ambientais. Compreendem-se então desta forma, que os espaços naturais e humanizados estão organizados diferentemente, apresentando muitas vezes, uso dos recursos naturais e a ocupação da terra bem definido e diversificado, em contextos, características físicas e naturais semelhante.

Para Christofoletti (1998), tais diferenças têm assim origem cultural, manifestando-se por meio da ocupação e do estabelecimento de atividades produtivas, do usufruto dos recursos naturais e da modificação dos aspectos do meio ambiente, influenciando as características visuais das paisagens e seus fluxos, modificando o equilíbrio natural. Estas manifestações permitem constatar que, as formas de uso do solo, os níveis de preservação e conservação dos recursos naturais, ou a problemática geral do meio ambiente, devem ser consideradas como resultado das ações antrópicas.

Ao longo da história, no processo de valorização e apropriação dos recursos naturais, o homem proporcionou diversas modificações no seu relacionamento com a natureza, resultando em diferentes níveis de intervenção e de impactos no meio ambiente, causando a poluição, a redução do número de espécies e de estoques, o assoreamento, o desmatamento, entre outros. As transformações dos ecossistemas naturais são resultados de uma série de acontecimentos naturais ou antrópicos, que geralmente se traduzem em muitos dos impactos provocados ao meio ambiente, principalmente em decorrência das atividades humanas relacionadas à ocupação e uso do solo de forma irracional (SANTOS, 2008; 2009).

Diante desta constatação, segundo Anjos (1993), o impacto ambiental pode ser considerado como: qualquer alteração das propriedades físicas, químicas ou biológicas do meio ambiente, causada por qualquer agente resultante das atividades humanas, quer seja de forma direta ou indireta, afetando a saúde, a segurança e bem estar do meio, bem como, a qualidade de qualquer recurso mineral ou vegetal, a exemplo do que ocorre no Complexo Estuarino Lagunar MundaúManguaba. Nesse sentido, é que se pretende caracterizar os processos naturais e antrópicos que resultam no processo de assoreamento nos canais interlagunares, como sendo responsável pela modificação em todo o CELMM. Estabelecendo-se para isso critérios que permitem fazer uma correlação entre a dinâmica natural e as alterações ocorridas nos elementos da paisagem local, 
em especial as lagunas são ambientes dinâmicos e distintos, onde ocorrem diferentes forças concorrentes, que agem para fornecer e distribuir as condições naturais necessárias para o seu equilíbrio. Desta forma, o estudo sobre a ocupação e o uso da terra nos ambientes lagunares em questão é importante a partir da influência que exercem na identificação das alterações e na caracterização da dinâmica natural da área estudada.

Os efeitos de tais eventos acima mencionados se fazem sentir com grande rapidez e de maneira continua em toda a sua extensão, afetando diretamente tanto os recursos naturais mais frágeis, extinguindo ou ameaçando exemplares de fauna e de flora, quanto o equilíbrio e a sustentação dos mesmos. Os projetos de modernização dos meios de produção são aplicados de maneira acelerada para atender a determinados interesses de produção e de consumo humano, trazendo problemas de difícil solução, como a poluição do ar, do solo e das águas, entre outros. Dessa forma, pode-se observar que, desde o seu aparecimento o homem vem promovendo alterações nos ecossistemas, ao apropriar-se dos recursos naturais, embora, sua intervenção tenha sido inexpressiva e pouco notada por milhares de anos ao longo da sua história, no qual a diferença contemporânea se deve á escala e ritmo dessas alterações (SANTOS, 2008).

As modificações ocorridas na área de abrangência dos canais interlagunares têm suas múltiplas facetas, sendo resultado de uma série de momentos cumulativos da organização da sociedade local. A interação destes fatos ao longo do tempo não deve ser encarada como um fato de forma isolado em si mesmo, já que a problemática ambiental, que á primeira vista restringe-se a uma relação homem-natureza, é uma realidade fundamentada na relação que o homem estabelece com o meio face ao seu processo de produção Este processo, seu ritmo e escala, está estritamente relacionado ao desenvolvimento tecnológico da humanidade, principalmente a partir da segunda metade do século XX, até então de certo modo, limitado nas suas alterações, não apenas em seu aspecto quantitativo, mas também, espacial (DOLLFUS, 1991).

Quando se fala em impactos ambientais, são feitas referências aos muitos problemas provocados ao meio ambiente e ao conjunto dos seus recursos naturais. Esta condição, ser originada em decorrência das atividades humanas de produção, ocupação e uso do solo ao longo da história do homem, seja pela ocupação ou utilização dos espaços, principalmente no processo de valorização dos recursos naturais, o que resulta assim, diferentes níveis de intervenção e de alterações nas condições de equilíbrio dos ecossistemas naturais. Alterações estas que sempre causam a poluição, a redução de espécies, o assoreamento e o desmatamento, a exemplo dos observados no CELMM. Os impactos ambientais podem ser observados com grande rapidez e de maneira continua, nos ecossistemas naturais mais frágeis, ameaçando exemplares da fauna e flora, quanto o equilíbrio, manutenção e continuidade. Estas alterações podem ser geradas por fatores diversos e constantes, sejam de origens naturais, ou humanas, ampliadas de acordo com as necessidades vigentes.

Segundo Christofoletti (1999), os problemas mais comuns, observados á primeira vista num determinado ambiente, não se restringe a uma relação homem-natureza, mas se fundamenta na relação que os grupos humanos estabeleceram entre si e em longo prazo, principalmente diante do processo de produção. Independente do uso definido ou não, os impactos ambientais promovem um grande número de reações diversas e, suas conseqüências em geral são negativas para o meio. Dessa forma, os impactos ambientais ocorridos na área dos canais interlagunares e manguezais, circunscrito ao CELMM apresentam-se sob múltiplas facetas, resultantes, sobretudo, de uma série de acontecimentos cumulativos da organização da produção e uso do solo.

\section{METODOLOGIA}

A metodologia foi direcionada para geração do mapa de uso da terra e cobertura vegetal, e seus respectivos impactos. Para isso foram utilizados: (a) carta topográfica da Região Nordeste do Brasil na escala 1:100 000, com eqüidistância entre curvas de nível igual de 40 metros, projeção Universal Transversa de Mercator (formato vetorial), referentes a Folha Maceió - SUDENE SC.25-V-C-IV (MI-1600) (1989) e (b) Imagem Spot (Satellite Pour l'Observation dev la Tierra) do CNES (Centro National d'Etudes dos Spatiales), composição colorida, bandas R2G3B4, com resolução espacial de 10 metros, ano de 2002 (Figura 2). 
A delimitação do CELMM foi baseada a partir da sua bacia de contribuição, obtidos na carta topográfica da SUDENE, folha Maceió, na escala 1:100.000, levando em consideração a união pontos cotados de maior valor; a interseção da convexidade das curvas de nível que apontam para linhas de cumeadas ou tergo; a união de ponto médio de interseção de cabeceiras de drenagem e a influência da maré, limitado pelos pontos cotados de 4 metros, dentro de ambientes vegetacionais de características estuarina-lagunar.

Figura 2. Parcial da imagem SPOT e delimitação do CELMM.

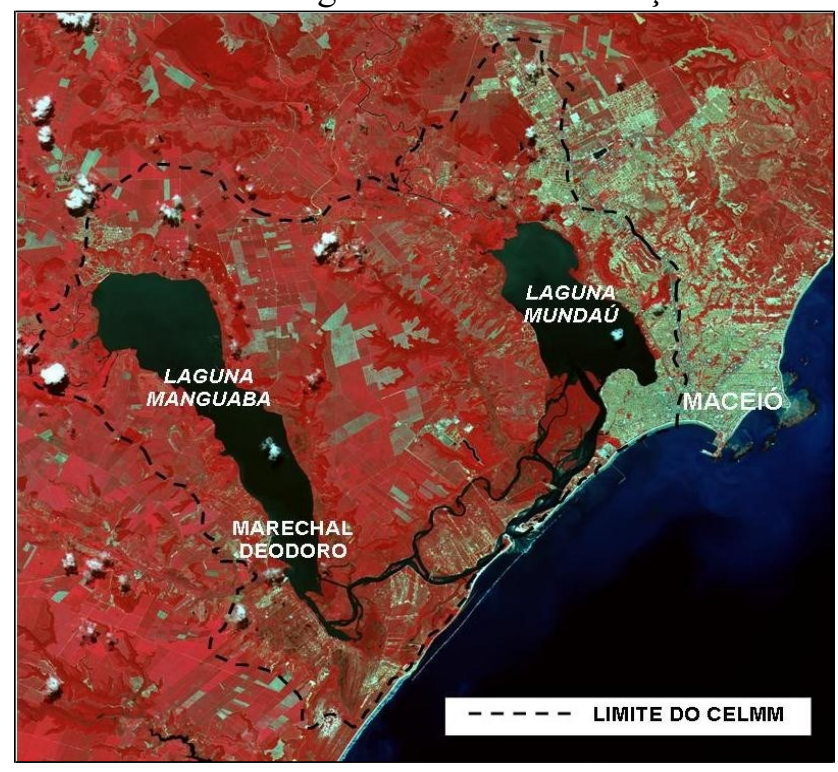

A interpretação visual da imagem constitui-se na definição de uma "chave de interpretação" para as categorias do mapeamento do uso da terra e cobertura vegetal, usando as bandas 2 (0.76-0.90 $\mu \mathrm{m}), 3(1.55-1.75 \mu \mathrm{m})$ e $4(0.63-0.69 \mu \mathrm{m})$. A chave de identificação foi definida a partir dos elementos identificadores do tema na imagem, tendo como referência os trabalhos desenvolvidos por Garcia (1986), Pereira, et al., (1989); Avery e Berlin (1992), Calheiros (1993), Meneses et al. (2001), Novo e Ponzoni (2001), Florenzano (2002), Moreira (2007), Rosa (1990 e 2009), Novo (2010), os quais são: tonalidade/cor, textura, forma, sombra, altura, padrão e localização. Os elementos sombra e altura foram desconsiderados visto que a imagens não apresenta muita cobertura de níveis, bem como, áreas urbanizadas com a presença de prédios do tipo "arranha-céus".

O mapeamento de uso da terra e cobertura vegetal seguiu os critérios da classificação do sistema de uso da terra proposto pelo Brasil (1999) e do sistema fisionômico-ecológico da classificação da vegetação brasileira adaptada a um sistema universal proposta por Henrique Pimenta Veloso e executadas pelo Projeto Radambrasil na década de 1970 e 1980, consolidadas na década seguinte por Veloso et al. (1991). Com referência a classificação da cobertura vegetal, quatro classes foram mapeadas: a floresta ombrófila secundária/descaracterizada, o cerrado e as formações pioneiras flúvio-marinhas e flúvio-lacustres, conforme mapeamentos realizados por Gonçalves e Orlandi (1983); Sarmento e Chaves (1986) e Assis (1998), nas respectivas escalas 1:1.000.000, 1:400.000 e 1:250.000.

O mapeamento dos níveis de impactos do uso da terra seguiu critérios propostos por Brasil (1999). As atividades humanas apresentam um nível de degradação ambiental e, segundo o nível de manejo de cada uma, variam da mais impactante para a menos impactante, variando 1 a 15. No trabalho em tela foi considerada a inversão dos valores do uso: do menos impactante ao mais impactante. Foi criada ainda, uma escala do grau de impactos ambientais relacionando aos quinze tipos supracitados, tendo como referência a proposta de Troppmair apud Calheiros (1993) distribuída em nove níveis de impactos na cobertura vegetal do 
CELMM, anos de 1965 -1989/1990. Finalmente foi realizada a relação dos níveis de impactos do uso da terra e cobertura vegetal do CELMM. Através da interpretação da imagem do sensor SPOT, as cartas topográficas da Sudene e os levantamentos de campo, dez categorias foram identificadas e mapeadas, sendo quatro classes de uso da terra, com destaque para as duas classes com maior ocorrência e extensão: sítios urbanos e campo sujo/limpo (pecuária extensiva: pastagens); e seis classe naturais, sendo as de maior ocorrência: floresta ombrófila secundária/descaracterizada e as formações pioneiras flúviomarinhas e flúvio-lacustres. Quanto aos impactos foram identificados e mapeados quatro tipos: fraco baixo, fraco médio, muito forte baixo e muito forte médio.

A edição da imagem consistiu no uso de técnicas de geoprocessamento aplicadas do SAGA/UFRJ. Para as classes de uso da terra foi utilizado o módulo Criar-SAGA versão 0.932 (beta) de 28/08/2003 - LAGEOP/UFRJ, que permite a vetorização de entes por meio de pontos, linhas e áreas, sendo possível ainda, atribuir cores e agrupar novas categorias. Paralelo a isso, foram realizadas visitas de campo objetivando identificar a fidedignidade das categorias de uso da terra e cobertura vegetal geradas na interpretação, eliminando possíveis dúvidas. Essa etapa consistiu na seleção de oito pontos de controle na imagem, os quais foram checados no campo. Posterior a aplicação de técnicas de geoprocessamento aplicadas, os dados foram tratados por meio de números absolutos e percentuais, possibilitando assim, a apresentação dos resultados e discussões.

\section{RESULTADOS E DISCUSSÃO}

Os levantamentos realizados de acordo com as classes identificadas no mapeamento de uso da terra (Tabela 1 e Figura 3) mostram a predominância das categorias antrópicas com 56,87\% sobre as categorias naturais, com 43,13\%, ou seja, mais da metade do CELMM apresenta algum impacto do uso da terra, identificados segundo a metodologia, e mapeados como fraco médio, fraco alto e muito forte médio (Figura 4).

Tabela 1. Uso da terra e cobertura vegetal do CELMM - Alagoas - Brasil em 1985

\begin{tabular}{|c|c|c|c|}
\hline Classes & Área (ha) & $\%$ & Impacto do uso da terra \\
\hline Ambientes naturais & 20910,16 & 43,13 & - \\
\hline Floresta ombrófila & 6309,75 & 13,01 & 0 -sem impacto \\
\hline Floresta estacional & 1219,02 & 2,51 & 0 -sem impacto \\
\hline Cerrado & 55,07 & 0,11 & 0 -sem impacto \\
\hline Formação pioneira flúvio-lacustre & 2053,2 & 4,24 & 0 -sem impacto \\
\hline Formação pioneira flúvio-marinha & 2566,17 & 5,52 & 0 -sem impacto \\
\hline Formação pioneira marinha & 205,12 & 0,43 & 0 -sem impacto \\
\hline Praia & 160,44 & 0,33 & - \\
\hline Rede de drenagem & 8232,87 & 16,98 & - \\
\hline Ambientes antrópicos & 27569,19 & 56,87 & - \\
\hline Pastagem + campo sujo/limpo & 3080,02 & 6,36 & 5-fraco médio \\
\hline Coco-da-baía & 4170,04 & 8,60 & 6-fraco alto \\
\hline Cana-de-açúcar & 14600,74 & 30,12 & 13-muito forte baixo \\
\hline Sítio urbano e ocupações rarefeitas & 5401,96 & 11,14 & 14-muito forte médio \\
\hline Sítio Industrial & 289,55 & 0,6 & 14-muito forte médio \\
\hline Corte de barreira & 26,88 & 0,05 & 14-muito forte médio \\
\hline Área total & 48479,16 & 100,00 & - \\
\hline
\end{tabular}

O CELMM é marcado atualmente pela forte interferência humana onde ocorre algum tipo de ocupação e uso da terra. Essa condição pode ser explicada em parte pela sua beleza cênica e a proximidade com a capital Maceió, o que supostamente cria assim, uma grande dinâmica populacional e de serviços. 
Entre os impactos do uso da terra, destaca-se (a) forte baixo (cana-de-açúcar), com 30,12\%, que abrange praticamente os topos dos tabuleiros entre as lagunas Mundaú e Manguaba; (b) muito forte médio (sítio urbano, ocupações rarefeitas, sítio industrial e corte de barreiras) com quase $11,79 \%$, correspondendo na sua maioria, o sítio urbano de Maceió; (c) fraco alto (coco-dabaía), com 8,60\%, ocorrendo de forma predominante na ilha de Santa Rita e nas margens dos canais interlagunares e nos arredores dos sítios urbanos de Marechal Deodoro e Pilar; (d) fraco médio (pastagens e/ou campo sujo/limpo) com 6,36\%, abrangendo parte das encostas e áreas que margeiam as lagunas Mundaú e Manguaba.

Figura 3. Uso da Terra em 2009 no CELMM, Alagoas (Brasil)

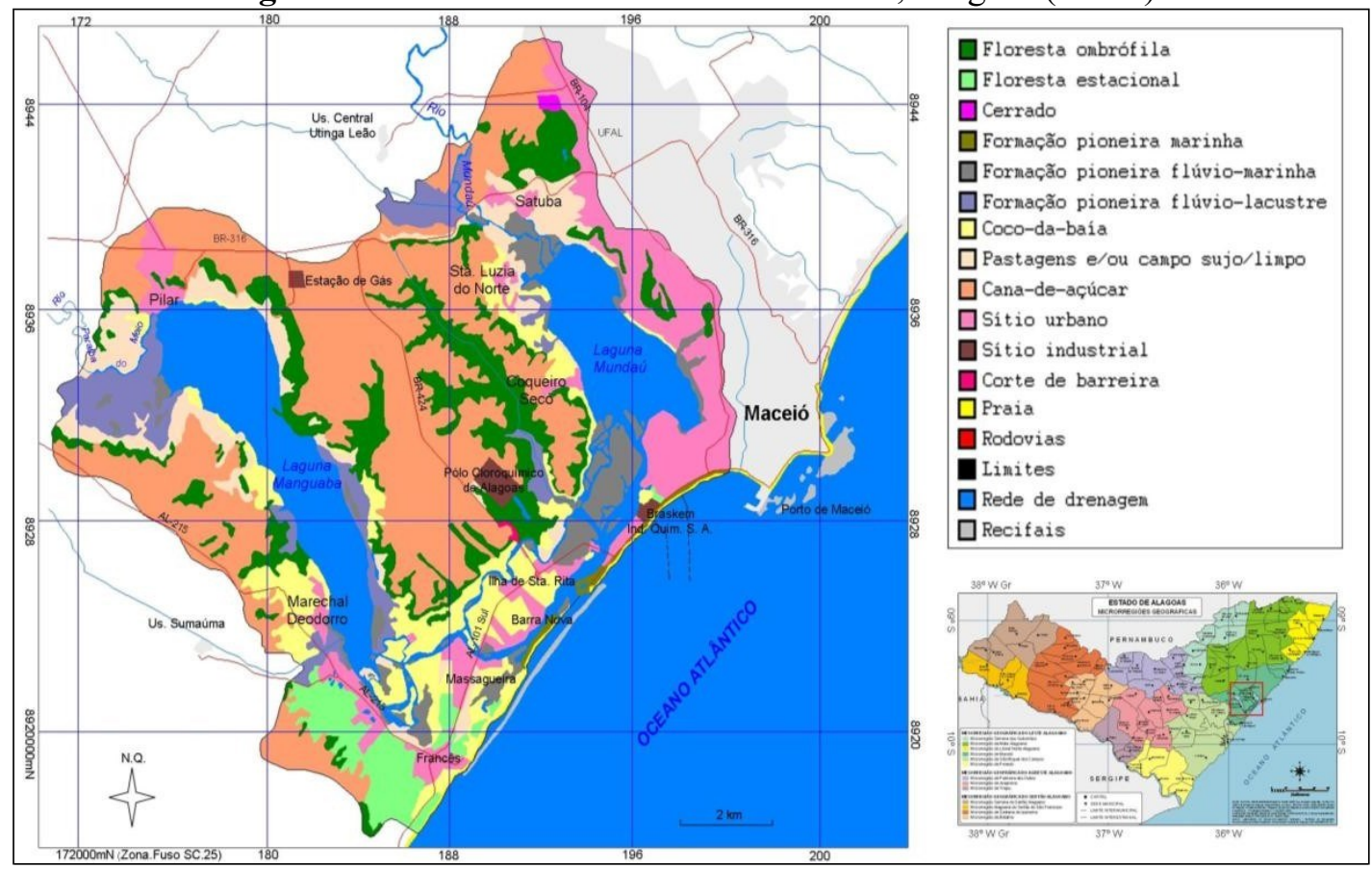

Figura 4. Impactos do Uso da Terra em 2009 no CELMM, Alagoas (Brasil)

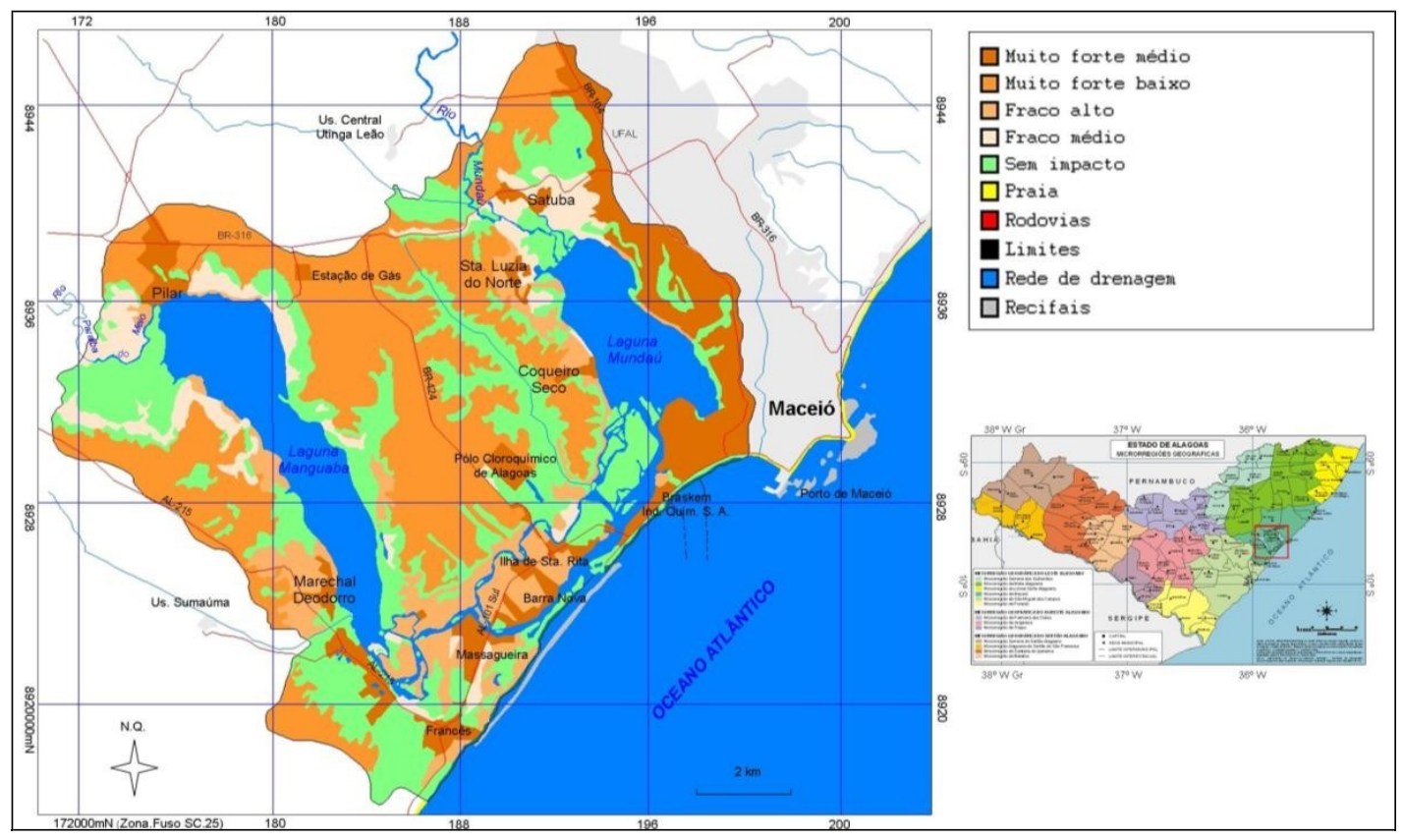

Os ambientes naturais, ou seja, que não sofreram impacto direto do uso da terra, abrange 
atualmente pouco mais de $43,13 \%$ do CELMM, incluindo-se também, a rede de drenagem $(16,98 \%)$ e a praia $(0,33 \%)$. Considerando apenas a cobertura vegetal, os ambientes naturais somam apenas $26,15 \%$ do CELMM. Eles são compostos na sua maior parte por remanescentes de florestas ombrófila $(13,01 \%)$, formações pioneiras flúvio-marinhas $(5,52 \%)$, flúvio-lacustres $(4,24 \%)$, e ainda, pequenas áreas de florestas estacionais $(2,51 \%)$, formações pioneiras marinhas $(0,43 \%)$ e de cerrado $(0,11 \%)$.

Nesse sentido, fatos preocupantes são observados com respeito aos impactos do uso da terra no CELMM, em especial nas áreas protegidas por lei, ou seja, as Áreas de Preservação Permanente (APPs), descritas no Código Florestal Brasileiro e nas Resoluções do Conselho Nacional do Meio Ambiente (Conama), como: as encostas com $45^{\circ}$ ou mais de declividade, margens de rios, nascentes e reservatórios naturais e/ou artificiais, bordas de tabuleiros.

\section{CONCLUSÃO}

$\mathrm{O}$ uso da terra no CELMM permite inter-relacionar um conjunto de problemas ambientais perfeitamente configurados, sobretudo destacando-se aqueles que têm levado o mesmo, paulatinamente a exaustão.

Os problemas ambientais no CELMM são visíveis e crescentes, no entanto o poder público competente não tem promovido ações eficientes no sentido de amenizá-los, isso causa a degradação dos ecossistemas dos quais dependem direta ou indiretamente os habitantes que ali residem. Os vários problemas existentes exigem uma série de medidas que devem ser urgentemente tomadas, como tratamento de esgotos, controle desmatamento e construções irregulares nas margens dos canais, controle de efluentes dos setores sucro-alcooleiro, cloroquímico e petroquímico. Para isso, é preciso a execução de um Plano de Gestão e Manejo Ambiental, visando à proteção (conservação/preservação) e recuperação dos seus ecossistemas, sobretudo das unidades de conservação inseridas no CELMM.

Entre os diversos mecanismos de promoção do desenvolvimento sustentável, destaca-se a educação ambiental como fator de vital importância, para promover um melhor entendimento e redirecionamento das atividades humanas, dentro de uma relação mais articulada, garantindo dessa forma a proteção dos seus recursos naturais e a qualidade de vida de sua população.

\section{REFERÊNCIAS}

ALAGOAS, Governo do Estado de Alagoas, SEPLAN, Secretaria de Planejamento, CDCT, Coordenação de Desenvolvimento Científico e Tecnológico, NMRH, Núcleo de Meteorologia e Recursos Hídricos. Hidroclimal. (Org. Centeno, J. A., Kishi, R. T.) Edição Especial. Maceió: 1992, 39p.

ALAGOAS, Governo do Estado de Alagoas, SEPLAN, Secretaria de Planejamento, CDCT, Coordenação de Desenvolvimento Científico e Tecnológico, NMRH, Núcleo de Meteorologia e Recursos Hídricos. Os Recursos hídricos do Estado de Alagoas (Org. Centeno, J. A., Kishi, R. T.) Maceió: Sergasa S. A., 1994. 41p.

ALAGOAS, Governo do Estado de Alagoas, Secretaria de Planejamento, Instituto do Meio Ambiente. Guia do Meio Ambiente: Litoral de Alagoas. Planejamento e Coordenação Geral de Valéria Salles. 3. ed. Maceió: Projeto IMA-GTZ, 1995. 177p.

ALAGOAS. Secretaria de Meio Ambiente e Recursos Hídricos do Estado de Alagoas. Plano Diretor de Recursos Hídricos das Bacias dos Rios Paraíba, Sumaúma e Remédios. Alagoas, 1997. 69 p.

ANDRADE, M. C. Paisagens e problemas do Brasil. 5. ed. São Paulo: Brasiliense, 1977. 288p.

ANJOS, C. A. M. DOS. Análise de impactos ambientais. (Apostila) Maceió, Universidade Federal de Alagoas, Geografia e Meio Ambiente, Curso de Pós-Graduação (Especialização), 2003, 69f. Mimeografado. 
ASSIS, J.S. Um projeto de Unidades de Conservação para o estado de Alagoas. Rio Claro, 1998. 241 f. Tese (Doutorado em Geografia - Organização do Espaço) - Universidade Estadual Paulista Júlio Mesquita Filho.

AVERY, T. E.; BERLIN, G. L. Fundamentals of remote sensing and airphoto interpretation. 5. ed. New Jersey: Prentice Hall. 1992. 472p.

BRASIL, Fundação Instituto Brasileiro de Geografia e Estatísitca - IBGE. Manual técnico de uso da terra/ [coordenadora Helge Henriettte Sokolonski], - Rio de Janeiro: IBGE, Departamento de Recursos Naturais e Estudos Ambientais, Primeira Divisão de Geociências do Nordeste, 1999. 58p. - Manuais técnicos em geociências, ISSN 0103-9598; n. 7.

CALHEIROS, S. Q. C. Impactos na Cobertura Vegetal no Complexo Estuarino Lagunar MundaúManguaba de 1965/1990. Rio Claro, 1993, 136f. Dissertação (Mestrado em Geografia) - Universidade Estadual Paulista Júlio Mesquita Filho.

CHRISTOFOLETTI, A. Geografia e meio ambiente no Brasil. 2. ed. São Paulo: Hucitec, 1998. 397p.

DOLLFUS O. O espaço geográfico. 5. ed. Rio de Janeiro: Bertrand Brasil, 1991. 121 p.

DREW, D. Processos interativos homem-meio ambiente. 3. ed. Rio de Janeiro: Bertrand Brasil, 1994. 224 p.

FEIJÓ, F. J. Bacia de Sergipe Alagoas. Rio de Janeiro. Geociências: Revista da Petrobrás, Rio de Janeiro, 8(1): 149-161 p., jan./mar., 1994.

FLORENZANO, T. G. Iniciação em sensoriamento remoto. São Paulo: Oficna de Textos, 2002. 128 p.

GARCIA, G. J. Sensoriamento remoto: princípios e interpretação de imaqens. São Paulo: Nobel, 1986. 357p.

GARCIA, G. J. Sensoriamento remoto: princípios e interpretação de imagens. São Paulo: Nobel, 1986. 357p.

GONÇALVES, L.M.C.; ORLANDI, R.P. Vegetação: as regiões fitoecológicas, sua natureza e seus recursos econômicos - estudo fitogeográfico. In: Brasil, Ministério das Minas e Energia, Secretaria Geral, PROJETO RADAMBRASIL. Folhas SC. 24/25 Aracaju/Recife. Rio de Janeiro, 1983. p. 573-652. (Série: LRN. V. 30).

LIMA, I. F. Maceió - a cidade restinga: contribuição ao estudo geomorfológico do litoral alagoano. Maceió: Edufal, 1990. 255p.

MARQUES, R. C. C. Estudo do uso do solo do no Complexo Estuarino-Lagunar MundaúManguaba. Maceió: Brasil, Superintendência de Desenvolvimento do Nordeste; Alagoas, Secretaria de Planejamento, Centro de Desenvolvimento Científico e Tecnológico, 1980. 235p. Mimeografado.

MARQUES, R. C. C. Geomorfologia e evolução da região costeira do Complexo Estuarino-Lagunar Mundaú-Manguaba. Rio de Janeiro, 1987, 151 f. Tese (Mestrado em Geografia) - Universidade Federal do Rio de Janeiro, 1987.

MARQUES, R. C. C.; LEMOS, R. P. de L.; RODRIGUES, M. N. Processo de ocupação e uso do solo da paisagem caeté aos dias atuais. In: NORMANDE, E. (Org.). Apoio à proteção ambiental em Alagoas: uma experiência de cooperação técnica. Maceió: Alagoas, Secretaria de Planejamento, Instituto do Meio Ambiente de Alagoas; Deustschegesellschaftfür Technischezusammenarbeit (GTZ) GMBH, 2000, Cap. 03, 17-27p.

MOREIRA, M. A. Fundamentos de sensoriamento remoto e metodologias de aplicação. São José dos Campos: INPE, 2001.

NOVO, E. M. L. de M. Sensoriamento Remoto. Princípios e aplicações. 4. ed. São Paulo: Edgard Blucher, 2010. 387p.

NOVO, E. M. L. M. Sensoriamento remoto: princípios e aplicações. 2.ed. São José dos Campos, SP: Edgard Blücher, 1992. 308p.

NOVO, E. M. L. M.; PONZONI, F. J. Introdução ao sensoriamento remoto. São José dos Campos, SP: Instituto Nacional de Pesquisas Espaciais - INPE, 2001, 68 p.

PEREIRA, M. N. et al. Cobertura e uso da terra através de sensoriamento remoto. [S.1.]: Presidência da República, Secretaria Especial da Ciência e Tecnologia, Instituto de Pesquisas Espaciais - INPE, 1989. 118p.

PEREIRA, M. N., et al.. Cobertura e uso da terra através de sensoriamento remoto. São José dos Campos: Presidência da República, Secretaria Especial da Ciência e Tecnologia, Instituto de Pesquisas Espaciais - INPE, 1989. 118p. (INPE-5032-MD/0420).

ROSA, R. Introdução ao sensoriamento remoto. 7. ed. Uberlândia: Edufu, 2009. 264p. 
ROSA, R.. Sensoriamento ao remoto. Uberlândia, EDUFU, 1990. 136p.

SANTOS, M. A natureza do espaço: técnica e tempo, razão e emoção. 4. ed. São Paulo: Edusp, 2009. 384 p.

SANTOS, M. Metamorfoses do espaço habitado: fundamentos teóricos e metodológicos da geografia. 6. ed. São Paulo: Edusp, 2008. 132 p. (Coleção Milton Santos; 10.)

SARMENTO, A. C.; CHAVES, L.F.C. Vegetação do estado de Alagoas: as regiões fitoecológicas, sua natureza e seus recursos econômicos - estudo fitogeográfico. In: Brasil, Ministério das Minas e Energia, Secretaria Geral, PROJETO RADAMBRASIL; Alagoas, Empresa de Desenvolvimento dos Recursos Naturais. Salvador; Maceió, 1985. 68 p. Mimeografado.

VELOSO, H. P. et al. Classificação da vegetação brasileira, adaptada ao um Sistema Universal. Rio de Janeiro: IBGE, 1991. 124 p. 